\title{
rhomboid, a gene required for dorsoventral axis establishment and peripheral nervous system development in Drosophila melanogaster
}

\author{
Ethan Bier, Lily Y. Jan, and Yuh Nung Jan \\ Howard Hughes Medical Institute and the Departments of Physiology and Biochemistry, University of California, San \\ Francisco, California 94143 USA
}

\begin{abstract}
rhomboid (rho) belongs to a group of four genes involved in the elaboration of positional information at a ventrolateral level in the Drosophila embryo. Mutations at any of these four loci also lead to a variety of other phenotypes, including reduction in the number of stretch receptor organs (chordotonal organs) in the peripheral nervous system (PNS). We have cloned rho with the aid of a lacZ-bearing P-element inserted into the rho gene. In the early blastoderm stage, a putative rho transcript is expressed in ventrolateral strips corresponding to the domain of activity of the rho gene on the embryonic fate map. Later expression of the transcript correlates with regions of the embryo that are disrupted in rho mutants and includes a cell that may be the precursor for the missing stretch receptor organs. We hypothesize that rho acts very early in differentiation pathways to specify the identities of domains and isolated precursor cells. Sequence analysis suggests that this transcript codes for a trans-membrane protein.
\end{abstract}

[Key Words: rhomboid; dorsoventral axis; spitz group; peripheral nervous system; lacZ; Drosophila melanogaster]

Received October 2, 1989; revised version accepted November 20, 1989.

Positional information along the dorsoventral axis of developing Drosophila embryos is specified by genes expressed maternally in the egg (Anderson et al. 1985a,b), as well as by genes that become active in the zygotic embryo (Jürgens et al. 1984; Nüsslein-Volhard et al. 1984). The former group of maternal-effect genes is assumed to generate a dorsoventral gradient of morphogen, which is read by the latter group of zygotic genes (Anderson 1987). The result of this genetic network may be the definition of a series of longitudinal strips of different dorsoventral positional cues. By the cellular blastoderm stage, cells of the Drosophila embryo have acquired specific fate according to their positions, so that different regions of the cellular blastoderm will give rise to different structures in a predictable manner, as defined by a fate map (Lohs-Schardin et al. 1979; CamposOrtega and Hartenstein 1985). Thus, the domains of activity of zygotic genes specifying position at the blastoderm stage may correspond to those regions of the Drosophila fate map, which give rise to tissues affected in the respective mutants. So far, molecular analysis of cloned genes of this type has been consistent with this expectation. For instance, the twist gene is required for defining the most ventral portion of the fate map, and twist is expressed in the most ventral region of the blastoderm (Thisse et al. 1988). Similarly, the longitudinal strips of the fate map requiring the activities of singleminded (sim), zerknüllt (zen), and decapentaplegic (dpp) all correlate with the regions of the blastoderm in which these genes are expressed (Doyle et al. 1986; St. Johnson and Gelbart 1987; Crews et al. 1988; Thomas et al. 1988).

Among the zygotic dorsoventral group of genes, those that specify positional information for cells situated in the ventrolateral domain, between the domains defined by $\operatorname{sim}$ and zen, are particularly relevant for neural development because both the central nervous system (CNS) and the ventral portion of the peripheral nervous system (PNS) arise from this region. These loci have not yet been characterized molecularly and include rhomboid (rho), Star (S), spitz (spi), and pointed (pnt) (Jürgens et al. 1984; Nüsslein-Volhard et al. 1984; Mayer and Nüsslein-Volhard 1988). The domain of the embryonic fate map affected by these genes is thought to be a longitudinal strip just dorsal to the mesectodermal domain defined by sim (Mayer and Nüsslein-Volhard 1988). Mutations in any of these genes lead to loss of ventral cuticular structures. In the CNS the spacing between the two longitudinal fiber tracks is also abnormal; it is much reduced in $S$, spi, and rho mutants but widened in pnt. These phenotypes have been interpreted as ventral midline defects (Mayer and Nüsslein-Volhard 1988; R. 
Jacobs, pers. comm.). Besides structures derived from the ventrolateral regions of the fate map, these mutations eliminate the first row of denticles in abdominal segments. The first row of denticles is thought to arise from the segment boundary. Defects in head development and dorsal closure are also observed in mutants for these genes. This last phenotype is seen in $r h o, S$, and pnt, but not in spi, mutants. Finally, $S$ and $s p i$ are required for formation of the germ line, as shown in studies involving pole-cell transplantation. In contrast, no maternal role for pnt or rho was observed. This has been taken as an indication that pnt and rho play specific roles in specifying positional information in the embryo, as opposed to providing a more general cell function (Mayer and Nüsslein-Volhard 1988).

Here, we report further phenotypic analysis, as well as molecular characterization of the rho locus. The variety of apparently unrelated structures altered by the rho mutation correlates well with the complex and dynamic expression pattern of the rho transcript. Thus, rho appears to act early in embryonic development to establish position along the dorsoventral axis and then again later to specify the fate of neuronal precursor cells. We propose that rho acts very early in a variety of developmental contexts to specify either the fate of cells in which it is expressed or the fate of cells in the immediate vicinity.

\section{Results}

\section{New alleles of rho}

Besides the original rho allele $r$ rho ${ }^{7 M 43}$, a new allele has been generated by insertion of a lacZ-containing $\mathrm{P}$ element, P-lacW (Bier et al. 1989). The insertion is at 62A on the third chromosome and disrupts the rho gene, because it fails to complement $r h O^{7 M 43}$. Revertants that appear to have resulted from precise excision of P-lacW sequences (see Methods), on the other hand, do complement $r h o^{7 M 43}$ and are viable. An imprecise excision that removes several hundred base pairs of DNA on one side of the P-lacW insertion has a cuticular phenotype similar to $\mathrm{rho}^{7 \mathrm{M}^{43}}$ and does not complement this mutation. Mutant embryos homozygous for the P-lacW insertion are similar to $r h o^{7 M 43}$ with regard to the PNS phenotype. They exhibit a cuticular defect that is less severe than that of $r h o^{7 M 43}$ or the deletion mutant, but they do not show any obvious CNS phenotype. Thus, the P-lacW insertion appears to have induced a weaker rho allele than $r h o^{7 M 43}$. This new allele is designated $r h o^{\text {lac1 }}$ and the deletion mutant derived from $r h o^{\text {Iac1 }}$ is called $r h o^{d e l 1}$.

\section{PNS phenotype of rho}

The embryonic PNS in abdominal segments is made up of three major clusters of neurons and support cells located at ventral, lateral, and dorsal levels. One type of sensory organ (chordotonal organ) is thought to be a stretch receptor. Chordotonal organs are present in both the lateral and ventral clusters of each abdominal seg- ment (Fig. 1C). In rho, as well as in $S$, spi, and pnt mutant embryos, two of the five lateral chordotonal organs are missing (Jan et al. 1986). In the ventral cluster, the chordotonal organ with the neuronal dendrite pointing ventrally is also frequently missing in rho mutants. Chordotonal organs in the thoracic segments of $r h o \mathrm{mu}-$ tant embryos, however, are normal.

Each chordotonal organ comprises four cells, a neuron, a scolopale cell that wraps around the dendrite of the neuron, and a cap cell and a ligament cell that attach to the epidermis. The four cells of a chordotonal organ are derived from a single precursor (Bodmer et al. 1989). Three of the four cells can be identified independently, as antibodies against horseradish peroxidase (antiHRP) label the neuron and scolopale cell (Jan and Jan 1982; Bodmer et al. 1987), the monoclonal antibody mAb44C11 labels neuronal nuclei (Bier et al. 1988), and the transformant line $\mathrm{A} 18$ expresses $1 a c Z$ ( $\beta$-gal) in the neuron, the scolopale cell, and the cap cell (Ghysen and O'Kane 1989). For those chordotonal organs absent in rho mutants, all three identifiable cells are removed (Fig. $1 \mathrm{~A}-\mathrm{Cl}$. Because the lacZ expression that results from the Al 8 insertion normally appears early, most likely in precursors of chordotonal organs as well, the total absence of such expression corresponding to chordotonal organs missing in rho mutants suggests that this gene acts early in the formation of chordotonal organs. Moreover, occasionally only one chordotonal organ is missing in a lateral cluster of the rho mutant embryo. In such cases, all identifiable cells of the four remaining chordotonal organs are present. The apparent all-or-none effect of the rho mutation on cells of a chordotonal organ again suggests that the mutation affects the precursor of the chordotonal organ.

To see whether rho mutations remove specific chordotonal organs, we used mAb49C4, which stains only four of the five chordotonal organs in wild-type embryos. The most anterior chordotonal organ does not express the mAb49C4 antigen (Bodmer et al. 1987). In rho mutants, three mAb49C4-positive cells are seen (not shown), suggesting that one of the missing chordotonal organs is the most anterior one.

To test whether all four genes involved in specifying the same ventrolateral domain of the blastoderm also affect the same chordotonal organs, we examined the embryonic phenotype of double mutants. The PNS phenotype for double mutants of both rho and pnt is the same as for rho or pnt alone. The same phenotype is also seen in double mutants of rho and $S$ or rho and spi. Thus, all of these genes appear to function in the formation of the same chordotonal organs.

Besides chordotonal organs, there are two other major classes of sensory cells in the PNS, namely neurons with multiple dendrites (md) and cells belonging to external sensory (es) organs. These cell types can be identified individually, using a variety of antibodies and lac $Z$ marker lines (Bodmer et al. 1987; Bier et al. 1989; Uemura et al. 1989). In abdominal segments, chordotonal organs seem to be the only PNS cell type deleted by the rho mutation; no effect on es organs or md neurons has been 


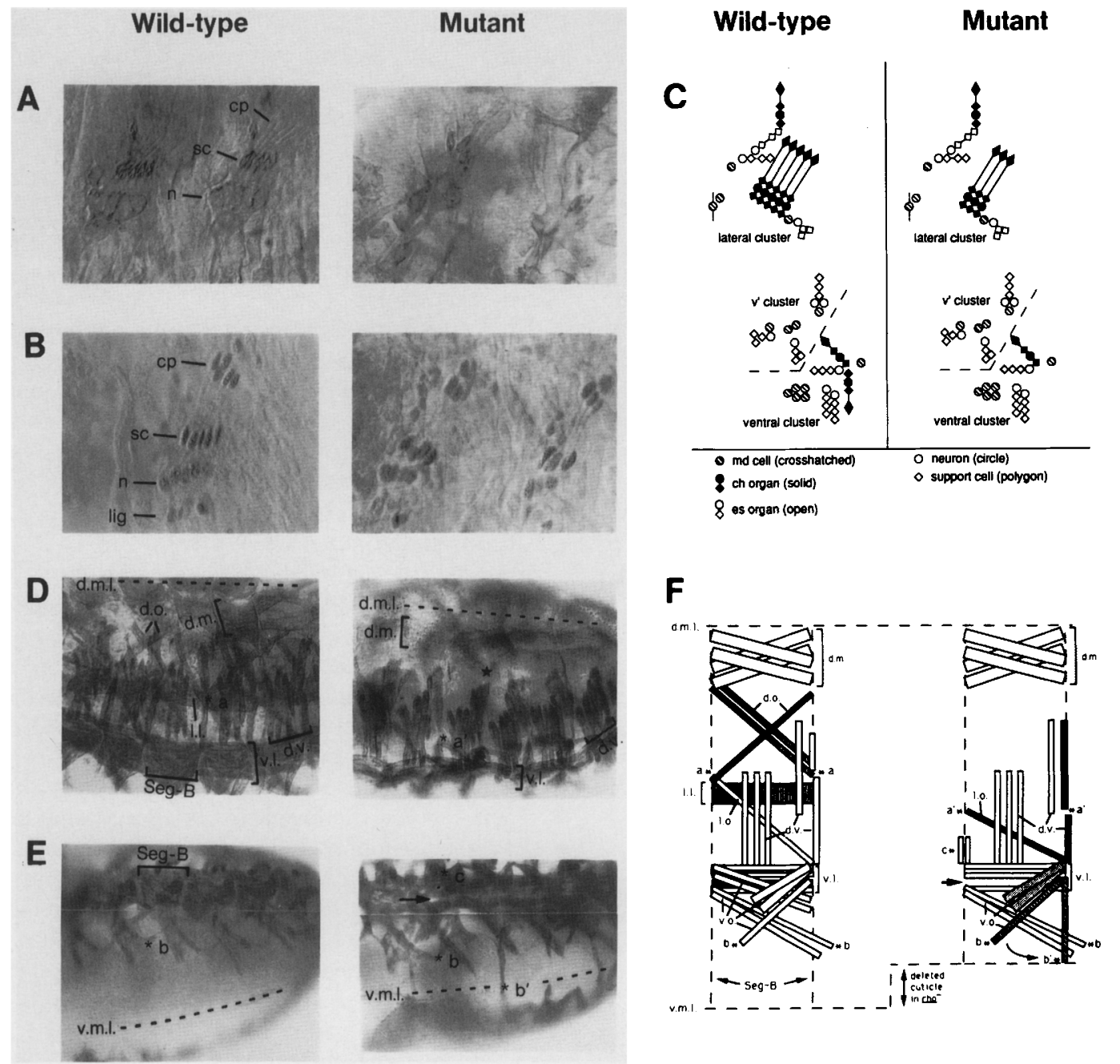

Figure 1. (See facing page for legend.)

found. In the thorax and head, on the other hand, es organs that are innervated by multiple neurons (e.g., Keilin's organs and the antennal maxillary complex) also show substantial reduction in cell number (not shown; see also Mayer and Nüsslein-Volhard 1988).

\section{Muscle phenotype}

The muscle pattern during mid-embryogenesis (10-11 $\mathrm{hr}$ ) is easily seen by staining with mAb6D5 (Caudy et al. 1988). In rho mutants, this pattern is abnormal. In thoracic segments, the muscle pattern is severely altered and the remaining fibers do not seem to follow a regular pattern. In abdominal segments, it appears that only a particular subset of muscles is affected and the altered pattern is regular from segment to segment (Fig. 1D-F). The dorsolateral longitudinal muscle and the dorsal oblique muscles, both with attachment sites within a dorsolateral strip of the embryo, are missing. This loss of muscles leads to a dorsolateral gap in the abdominal muscle pattern. No muscle fibers running along the dorsoventral axis are missing, however. The dorsal longitu- dinal muscle mass, which is found near the dorsal midline (lightly stained by $\mathrm{mAb} 6 \mathrm{D} 5$ ), contains muscles that are unaffected by the rho mutation and may also contain some of the muscle fibers missing from the normal dorsolateral position in rho mutant embryos. In the ventral region, certain muscles are also missing (Fig. 1E,F).

Some muscles are retained in mutant embryos, although the site to which they attach is altered. For example, in Figure 1D and F, muscles that normally attach to the site marked by an asterisk (a) join at the more ventral position marked by an asterisk $\left(a^{\prime}\right)$ in rho embryos. This shift is accompanied by a change in the relative length of fibers that run along the dorsoventral axis at the segment boundary, suggesting that the location of this attachment site determines the shape and course of the fibers that attach to it. In the ventral region, one of the ventral oblique fibers that crosses the segment boundary and becomes fastened at the site marked $b$ is found at a much more ventral location in rho mutant embryos. Often, these fibers take an abnormal dorsoventral path and attach to the ventral midline (labeled $b^{\prime}$ ), as do the corresponding fibers from the opposite hemiseg- 
ment. In general, muscles in ventral and lateral regions are displaced ventrally in rho mutant embryos, possibly as a secondary consequence of the loss of ventral epidermal structures. These observations suggest again that there is an intimate dependence of muscle development on the position of epidermal cues such as attachment sites. Because the fibers that are missing in the mutant are generally those with two segment-boundary attachment sites, and fibers running along the dorsoventral axis are retained, it is possible that defects at segment boundaries, as well as dorsoventral patterning, lead to loss of fibers or displacement of certain muscle attachment sites.

\section{Molecular analysis of the rho locus}

Genomic DNA flanking the P-lacW insertion in $r h o^{\text {lac1 }}$ was isolated by plasmid rescue (Pirrotta 1986). The rescued DNA fragments hybridize to the $62 \mathrm{~A}$ region on the polytene chromosome and have the same restriction map (Fig. 2A) as that of the genomic DNA determined by Southern analysis (not shown). On Northern blots, the genomic DNA fragment $(2.8 \mathrm{~kb})$ at the $5^{\prime}$ end of the Ptransposase-lac $Z$ fusion gene detects two bands $(2.5$ and $2.9 \mathrm{~kb}$ ) during all stages of development, with the exception of larval stages (Fig. 2B). Further Northern analysis showed that the 2.5- and 2.9-kb transcripts are present throughout embryogenesis but become more abundant after $12 \mathrm{hr}$. In contrast, no message was seen in ovaries, even with long exposure (not shown). The genomic DNA on the other side of P-lacW ( $3.4 \mathrm{~kb})$ gave only weak and diffuse signals on Northern blots of embryonic RNA. These weak signals may arise from some repetitive sequence in this region. When a probe including this fragment was used to screen a genomic library, many faintly positive plaques were seen in addition to the few strongly positive ones.

To better define the transcription unit near the P$1 a c W$ insertion of $r h o^{I a c 1}$, we isolated three cDNA clones that hybridize to the $5^{\prime}$ genomic fragment. Two of these are $\sim 2.5 \mathrm{~kb}$ long. They map back to a $4.7-\mathrm{kb}$ genomic region on Southern blots of both cloned and genomic DNA. When one of these cDNAs is used as a probe, on Northern blots the same transcripts are labeled as those that are labeled with the probe made from the rescued genomic DNA. A comparison between the sequence of the cDNAs and that of genomic DNA shows that this genomic region is interrupted by two introns (Fig. 2A). To determine whether this transcription unit corresponds to the rho gene, we transformed flies with an 8.3$\mathrm{kb}$ genomic fragment that includes the coding region for the 2.5-kb cDNA and $2.2 \mathrm{~kb}$ at its $5^{\prime}$ end (Fig. 2A; Rubin and Spradling 1982). In contrast to control rho mutant stocks in which the mutation is $100 \%$ embryonic lethal,

Figure 1. PNS and muscle phenotypes in rho mutant embryos. (A) Lateral chordotonal cluster in abdominal segments of rholac1/ $r h o^{l a c 1}$ mutant and wild-type embryos stained with an anti-HRP antibody. The neuron ( $\mathrm{n}$ ) and scolopale cell (sc) label with anti-HRP. The cap cell (cp) can be seen by Nomarski optics, but the ligament cell (lg) is not visible. $(B)$ lac $Z$ expression in chordotonal organ cells that results from the P-lac insertion in the A18 line (Ghysen and O'Kane 1989) in either the rholac1/rholac1 mutant or a wild-type background. Nuclei of the $\mathrm{n}, \mathrm{sc}$, and cp label strongly. In favorable preparations, the ligament cell can also be seen. Note one segment of this mutant embryo has four complete chordotonal organs, instead of three. In such cases, all three lacZ-expressing cells of the chordotonal organ are present in the fourth organ. $(C)$ Schematic representation of an abdominal hemisegment of mutant and wildtype embryos showing a loss of at least three of the four cells in each of the two missing organs in the lateral cluster. In the ventral cluster, the chordotonal organ that normally points ventrally is also frequently missing in rho embryos. (D) Lateral view of the muscle patterns in wild-type and $r h o^{7 M 43} / \mathrm{rho}^{7 M 43}$ mutant embryos visualized by staining with mAb6D5. The major muscle groups noted are dorsal oblique muscles (d.o.), dorsoventral muscles (d.v.), lateral longitudinal muscle (1.l.), dorsal muscles (d.m.), lateral oblique muscle (1.o.), ventral longitudinal muscles (v.l.), and ventral oblique muscles (v.o.). Other symbols are as follows: (d.m.l.) dorsal midline; (seg-B) segment boundary; (v.m.l.) ventral midline. Asterisks mark muscle attachment sites, as described below. Muscles marked with a star in the rho mutant embryo may include some of the missing d.o. fibers. $(E)$ Ventral view of muscles in wild-type and rho mutant embryos. Note the greater distance of the muscles from the ventral midline in wild-type versus rho mutant embryos. $(F)$ Schematic representation of the muscle pattern in an abdominal hemisegment in wild-type and mutant embryos. The wild-type scheme is modified from Campos-Ortega and Hartenstein (1985) and Crossley (1978). Muscles that are shaded in the wild-type diagram are consistently missing in rho embryos. Asterisks mark positions where multiple muscles attach in both wild-type and mutant embryos. The asterisk marked " $a$ " denotes the site at which the long and short d.v. fibers and the 1.o. muscle (from the next segment) are anchored. At the asterisk marked " $b$," two ventral oblique fibers from neighboring segments join. In rho mutant embryos, the following aberrations are observed and represented in the diagram. (1) Fibers are clearly missing - those that are shaded in the wildtype diagram. (2) Fibers are missing or aberrantly attached-among the v.l. fibers, there is nearly always a gap (large short arrow), which most likely results from the absence of one of the four v.l. fibers seen in wild-type embryos. Some v.o. fibers, which slant ventrally from anterior to posterior, are also missing, and the thick v.o. fibers, which slant ventrally from posterior to anterior (stippled), are occasionally absent. The absence of the v.l. and v.o. fibers in their normal locations, however, may not reflect a net loss of fibers, as ectopic fibers are seen clustered at the segment boundary in the region where these fibers usually make their most dorsal attachment ( $F$ and $E$; asterisk marked c). (3) Fibers make coherent but inappropriate attachments-the d.v. and l.o. fibers (solid shading) join at a common point ( $D$ and $F$; asterisk marked $\left.a^{\prime}\right)$, as is seen in the wild-type ( $F$; asterisk marked a in wild-type); however, the position of this common anchoring site is shifted ventrally from the wild-type pattern. Furthermore, the dorsal d.v. fiber is shorter in the wild-type configuration, whereas the ventral d.v. fiber is shorter in rho mutants. This is consistent with the idea that the muscle configuration is molded by the positions of the attachment sites. The ventral attachment site for one of the v.o. fibers is also ectopic in about half of the segments examined. In the wild-type configuration, this fiber (hatching) anchors at a site across the segment boundary $(F$ and $E$; asterisk marked $\mathbf{b})$, but in the mutant, this fiber runs ventrally along the segment boundary and frequently joins with the fiber from the opposite hemisegment at the ventral midline $\left(F\right.$ and $E$; asterisk marked $\left.b^{\prime}\right)$. This situation is never seen in wild-type embryos; normally, there is a clear gap that separates the ventral-most fibers of the two hemisegments. 
A
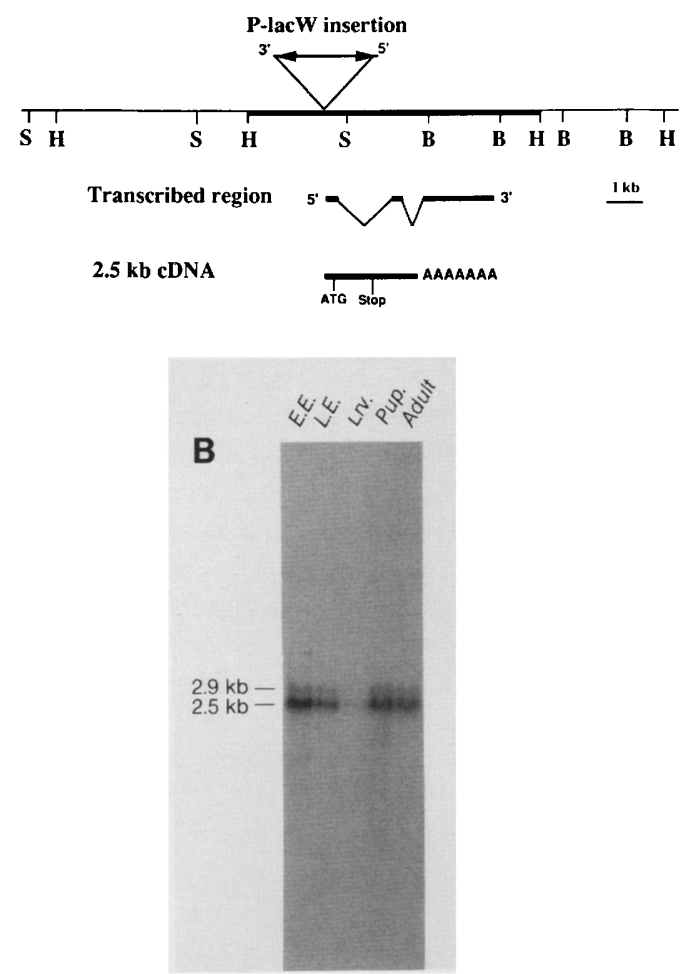

Figure 2. Molecular map of the rho locus. $(A)$ The site of PlacW insertion in rholac1 is 39 bp upstream from genomic sequences that correspond to the $5^{\prime}$ end of the longer of the two $2.5-\mathrm{kb}$ cDNAs (isolated from the T. Hsieh library). The direction of transcription of the $1 a c Z$ fusion gene in P-lacW is opposite that of rho. The protein-coding portion of the rho transcripts is delimited by the AUG translation start site and the stop termination codon (for details, see Fig. 3A). The $8.3-\mathrm{kb}$ HindIII fragment used for P-element transformation is shown by the thickened line. In the deletion mutant $r h o^{\text {del1 }}, 0.5-0.8$ $\mathrm{kb}$ of genomic DNA, $5^{\prime}$ to the P-lacW insertion site, is removed. Also eliminated by this deletion is $4.2-4.5 \mathrm{~kb}$ of $\mathrm{P}$ lacW DNA, resulting in loss of the lac $Z$ gene but retention of coding sequences in the white gene. The cDNA sequence is encoded from three genomic exons separated by introns of 1.55 and $0.6 \mathrm{~kb}$. Restriction enzymes are symbolized as (S) SacII, (H) HindIII, and (B) BamHI. $(B)$ Northern blot of poly $(A)^{+}$RNA $(10$ $\mu \mathrm{g}$ per lane] extracted from Drosophila embryos [1-14 hr, early embryonic (E.E.); 9-21 hr, late embryonic (L.E.), third instar larvae (Lrv.), pupae [(Pup.) 1-4 days old], and adults (males and females). The blot was hybridized with a probe derived from 2.8 $\mathrm{kb}$ of flanking genomic DNA at the $5^{\prime}$ end of the P-transposase-lac $Z$ fusion gene. Identical results were obtained using one of the $2.5-\mathrm{kb}$ cDNAs as probe. All lanes except the L.E. lane contain nearly equal amounts of RNA, as judged by rehybridizing the filter with an actin probe. Noticeably less actin signal was observed in the L.E. lane (data not shown).

$40 \%$ of the homozygous rho mutant embryos carrying two copies of the $8.3-\mathrm{kb}$ fragment hatch as viable larvae (Table 1). Substantial rescue of the rho cuticular phenotype is also observed by the introduction of two copies of this genomic DNA fragment (Table 1; Fig. 4). Thus, this region appears to include some rho function. Because
Northern analysis suggests that this fragment contains only one full transcription unit, this transcription unit most likely corresponds to the rho gene.

Sequence analysis of the $2.5-\mathrm{kb}$ cDNAs reveals a single long open reading frame coding for a protein of 355 residues (Fig. 3A). In rholac1, the P-lacW insertion is $39 \mathrm{bp}$ upstream from sequences corresponding to the $5^{\prime}$ end of the longer of the two cDNAs. The P-lacW insertion site is flanked by a consensus cap site sequence 25 bp downstream) and three potential TATA box sequences (the first of which is immediately upstream). Thus, the P-lacW insertion most likely reduces rho gene activity by separating coding sequences from the promoter. In the deletion mutant $r$ hodell, the entire exon coding for much of the $5^{\prime}$-untranslated sequence of this rho transcript is eliminated (Fig. 2 legend). This deletion may reduce rho activity even further than the original rho ${ }^{\text {lac1 }}$ insertion, leading to the more severe cuticular phenotype.

The predicted tho protein has a molecular weight of 39,356 and is most likely an integral membrane protein. The predicted number of membrane-spanning regions ranges from three to seven, depending on the algorithm used in the identification of hydrophobic segments (Fig. 3B). No hydrophobic signal sequence is present at the amino terminus, suggesting that this end may be cytoplasmic. A PEST sequence postulated to be associated with proteins of short half-life (Rogers et al. 1986) is found 45 amino acids from the amino terminus. In the 3 '-untranslated portion of the cDNA, 14 copies of the sequence ATTTA are found. This motif has been shown to cause rapid mRNA turnover and to lower translation efficiency (Shaw and Kamen 1986; Kruys et al. 1989). Thus, both the rho message and protein may be turned over rapidly. In the amino-terminal region there is a stretch of alternating positive and negative charges, similar to a sequence that is proposed to form an $\alpha$ helix in the c-fos and N-myc leucine zipper domains (Kohl et al. 1986; Landschulz et al. 1988). A similar sequence is also found and predicted to be cytoplasmic in the gene product of the maternal-effect Toll gene (Hashimoto et al. 1988; Fig. 3B).

In summary, the site of P-lacW insertion in $r h o^{1 a c 1}$ is likely to be in or downstream from the promoter of a transcription unit. The genomic fragment that includes this transcription unit rescues much of the rho embryonic mutant phenotype. Moreover, as described below, the complex and dynamic expression pattern of this transcription unit corresponds closely to those parts of the embryo affected by rho mutations. Therefore, this transcription unit is most likely the rho locus.

\section{Expression patterns of rho}

Expression of rho transcripts is dynamic and complex. The earliest expression is seen at the cellular blastoderm stage (Fig. 5A,B). In cross sections (Fig. 5A) this expression appears in two longitudinal ventrolateral domains seven to eight cells wide, with irregular boundaries both dorsally and ventrally. These domains are separated by 

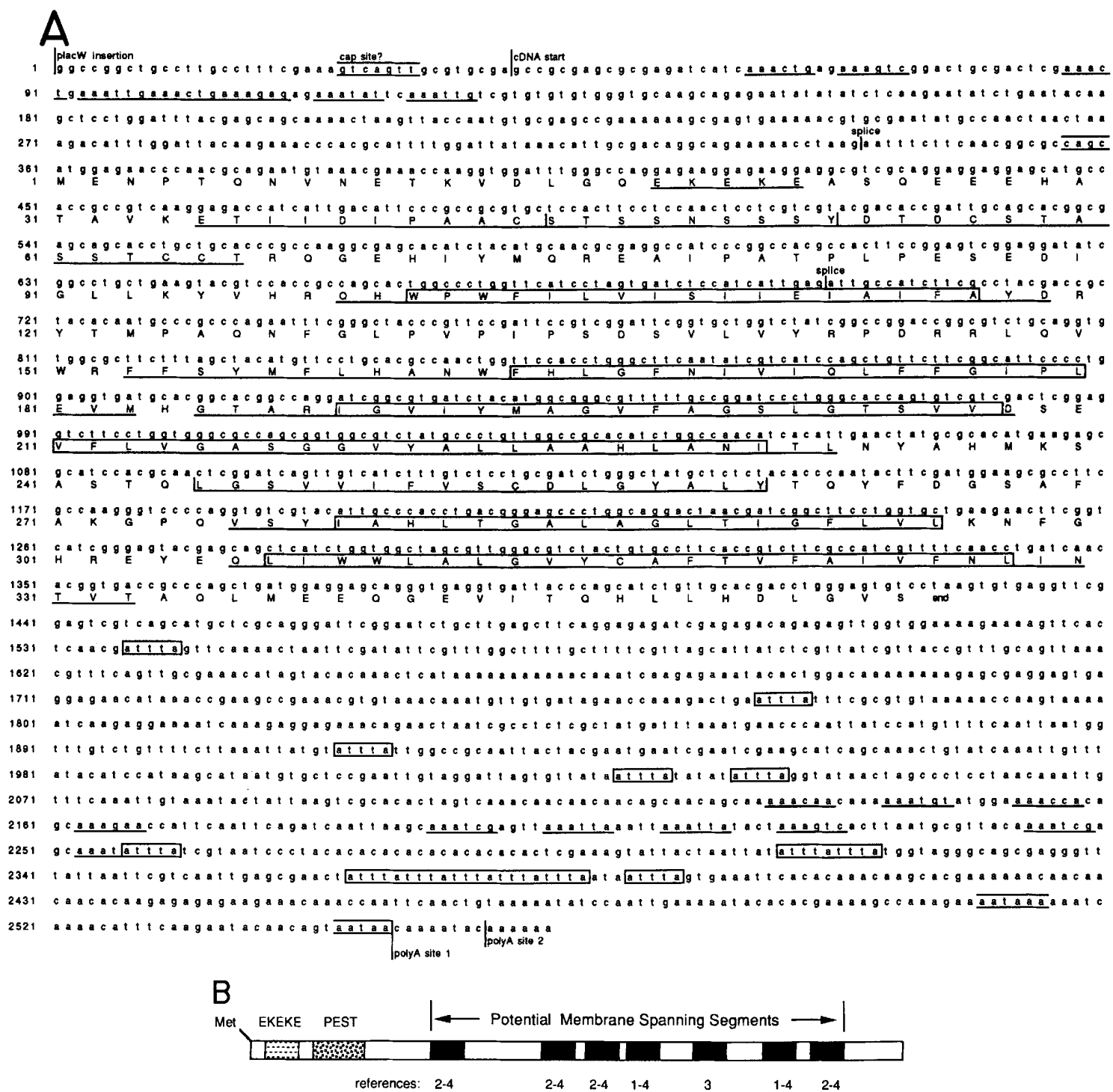

Figure 3. Primary sequence analysis of the $2.5-\mathrm{kb}$ rho cDNAs. (A) DNA sequence of the $2.5-\mathrm{kb}$ cDNAs. Opposite strands of two independently isolated $2.5-\mathrm{kb}$ cDNAs were sequenced. Both cDNAs yielded the same sequence. The cDNA sequence agrees with the sequence of genomic DNA; the latter also contains two introns. The first intron is located between nucleotides 339 and 340 . The donor and acceptor sequences are, respectively, AAG/gtaagc and tcctctctttctccag/AAT. The second intron is found between nucleotides 696 and 697. The donor and acceptor sequences are, respectively, GAG/gtaagc and tctctgtccattttag/ATT. The two junction sequences match the consensus donor and acceptor sequences $(\mathrm{C} / \mathrm{A}) \mathrm{AG} / \mathrm{gt} / \mathrm{a} / \mathrm{g})$ agt and $\left(\mathrm{t} / \mathrm{c} / \mathrm{n} \geqslant_{12} \mathrm{X} / \mathrm{t} / \mathrm{c}\right) \mathrm{ag} / \mathrm{XXX}$, respectively $(\mathrm{Mount}$ 1982). The sequence GTCAGTT is found 25 bp downstream of the P-lacW insertion site and matches closely the mRNA cap site consensus ATCA(G/T)T(C/T) for non-heat-shock insect genes (Hultmark et al. 1986). Three potential TATA box sequences are found 6,29 , and 72 bp upstream of the P-lacW insertion (not shown). The 5' end of the longest cDNA is noted in relation to genomic-coding sequences. Just preceding the proposed first methionine is the sequence CAGC, which is in agreement with the Drosophila translation start consensus (C/A)AA(C/A) (Cavener 1987). Multiple copies of the sequence motif ATTTA are found in the 3'-untranslated region. This motif has been shown to lead to mRNA instability (Shaw and Kamen 1986) and has also been implicated in translation control (Kruys et al. 1989). Repeats of the sequence AAAXTG are clustered in the first $100 \mathrm{bp}$ of the $5^{\prime}$-untranslated region, and similar repeats spaced with helical periodicity $(10 \mathrm{bp})$ are present in the $3^{\prime}$-untranslated region. The predicted protein sequence of the only long open reading frame is displayed, using the standard single-letter code for amino acids. Protein sequence motifs underlined are EKEKE, found in what would be predicted to be the amino-terminal cytoplasmic portion of the putative rho protein, a PEST sequence (Rogers et al. 1986), with a core sequence (STSSINSSY) similar to the PEST sequence found in the Drosophila achaete-scute T5 gene product STSSCNSISSY (Villares and Cabrera 1987). The boxed domains are regions where two or more computer programs (Eisenberg et al. 1984; Klein et al. 1985; Ralph et al. 1987; Rao and Argos 1986) predicted the same membrane-crossing domains, and the underlined segments in this region of the protein are predicted as possible membrane-spanning regions by only one/of the programs. $(B)$ Schematic representation of the putative rho protein. Marked structures correspond to those described in $A$. Solid boxes represent potential membrane-spanning regions. Numbers beneath the boxes refer to the programs that predict the segment to be trans-membrane: (1) Eisenberg et al.; (2) Rao and Argos; (3) Klein et al.; (4) Ralph et al. Segments four and six are predicted by all programs. The program of Ralph et al, run by T. Smith, suggests that segment two may form a $\beta$ sheet. The box filled with dashed lines denotes the charged domain containing the EKEKE sequence; the stippled box is the region containing the PEST motif. 
Table 1. Partial rescue of rho phenotype by the $8.3-\mathrm{kb}$ fragment

\begin{tabular}{|c|c|c|}
\hline \multicolumn{3}{|l|}{ A. Embryonic lethality } \\
\hline rho genotype & \multicolumn{2}{|c|}{$r h o^{l a c 1 / r h o^{7 M 43}}$} \\
\hline \pm RynA-3/RynA-3 & - & + \\
\hline$\%$ unhatched embryos & 25 & 15 \\
\hline total number tested $(N)$ & 139 & 1418 \\
\hline \multicolumn{3}{|l|}{ B. Length of first denticle band } \\
\hline $\begin{array}{l} \pm \text { RynA-3/RynA-3 } \\
\text { third abdominal segment }\end{array}$ & - & + \\
\hline$\%$ of wild type & $51 \pm 6$ & $81 \pm 6$ \\
\hline $\begin{array}{l}\text { total number tested } \\
\text { fourth abdominal segment }\end{array}$ & 81 & 86 \\
\hline $\begin{array}{l}\% \text { of wild type } \\
\text { total number tested }\end{array}$ & $\begin{array}{l}57 \pm 5 \\
81\end{array}$ & $\begin{array}{l}78 \pm 5 \\
86\end{array}$ \\
\hline
\end{tabular}

To get an estimate of the rho function provided by the $8.3-\mathrm{kb}$ genomic fragment within the RynA-3 P element on the X chromosome, we examined the effect of this RynA-3 insertion on the rho mutant phenotype, by measuring $(A)$ the percentage of unhatched embryos from heterozygous parents and $(B)$ the length of the first row of denticles in the third and fourth abdominal segments as normalized to that of wild-type embryos [mean \pm S.D. of the mean $(s)$ ]. Details of the crosses are provided in Methods. The significance of the difference in embryonic lethality in a $r h o^{l a c 1} / r_{h} o^{7 M 43}$ background was estimated by $z=\left(y / n-p_{o}\right) / \sqrt{p_{o}\left(1-p_{0}\right) / N}$; where $y / n$ is the observed fraction of unhatched embryos and $p_{o}=0.25$. For $r h o^{l a c 1 / r h o^{7 M 43}}$ embryos, $\mathrm{p}<0.001$ for the observed partial rescue of lethality. $r h o^{\text {Iac1 }} / r h o^{\text {lac } 1}$ is also completely embryonic lethal $124 \%$, $N=164)$. In addition, all cuticles from $r h o^{7 M 43} / r h o^{7 M 43}, r h o^{l a c 1 /}$ $r h o^{7 M 43}$, and $r h o^{l a c 1} / r h o^{l a c 1}$ dead embryos show defects in denticle belt morphology. Dead embryos of the RynA-3/RynA-3, $r h o^{\text {Iac1 }} /$ rhol $^{\text {lac1 } 1}$ genotype show a range of phenotypes but, overall, are clearly intermediate between $r h o^{l a c 1} / r h o^{l a c 1}$ and wild type. This effect has been quantitatively addressed by measuring the length of the first row of denticles in abdominal segments 3 and 4 in wild type, in $r$ holac1/rholac1, and in RynA-3/RynA-3, rholac1/ rholac1 embryos. For rescue of the cuticle phenotype, probability values $(\mathbf{p})$ were calculated, using $z=\left|y_{1}-y_{2}\right| / \sqrt{s_{1} / N_{1}+s_{2} / N_{2}}$; [y $=\left(\left(\Sigma X_{i} / d_{i}\right) / N\right) / y_{\text {wild-type, }}$ where $x$ is the length of the first row of denticles, $d$ is the width of the embryo in segment 3 and 4 , and $y_{\text {wild-type }}=0.43$ for segment 3 and 0.46 for segment 4; $s^{2}=\Sigma\left(X_{i}-X\right)^{2} / N-1$, where $N$ is the sample size and $X$ is the mean]. The significance of differences in length of the first row of denticles in $r h o^{\text {lac1 }} / \mathrm{rho}^{\text {lac1 }}$ mutants with versus without the RynA-3 element is p $<0.001$ for segments 3 and 4 . rholac1/ $r h o^{7 M 43}$ or $r h o^{7 M 43 / r h o^{7 M 43}}$ embryos generally lack the first row of denticles. Many embryos of these genotypes that also carry RynA-3 have distinct first rows. This effect is difficult to quantitate because there are also many embryos for which it is not obvious whether the first row is present, as denticle bands often interdigitate and follow irregular paths. The extent of rescue of the cuticular phenotype in rho mutant embryos carrying RynA-3 is an underestimate of the true average effect, as the $40 \%$ of transformant embryos that hatch were not scored. In fact, examination of dead first instar larvae on the grape plates revealed that the hatching larvae were rescued more completely than unhatched embryos on the same plate.

an unlabeled ventral strip that is $13-15$ cells wide. Shortly thereafter, expression appears in a dorsal strip as well, leading to signals in three approximately evenly spaced circumferential locations (Fig. 5C). Subsequently, the ventrolateral domains of expression become narrower and periodically modulated in intensity along the anterior-posterior axis. During this time, the ventrolateral strips become delimited by a sharp boundary ventrally (Fig. 5D). Horizontal sections and whole-mount preparations also reveal two stripes of expression in the head, running perpendicular to the long axis of the embryo (Fig. 5F). As mesoderm invagination begins, the label is moved ventrally and becomes progressively restricted to a single row of cells on each side of the embryo. These two rows meet at the ventral midline as the ventral furrow closes (Fig. 5E,G). Upon closure of the ventral furrow the labeled cells interdigitate to form a single mesectodermal strip along the ventral midline (Fig. $5 \mathrm{H}$ ). This expression remains until germ-band retraction.

Although the mesectoderm is labeled, strong but very transient expression is seen in cells in each abdominal hemisegment at the location of the invaginating tracheal

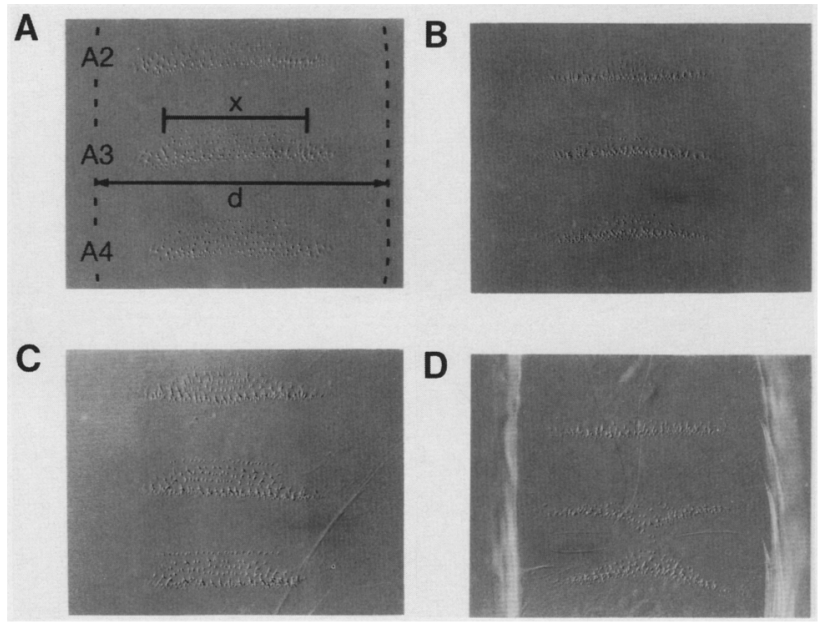

Figure 4. rho function is supplied by an $8.3-\mathrm{kb}$ genomic fragment. $(A)$ Wild-type denticle bands in abdominal segments (segments 2-4 are shown) are made up of six rows of denticles. In these segments, the first and fourth rows of denticles point anteriorly, in contrast to all other rows, which point posteriorly. As a measure of the extent of ventral cuticle structures, the length of the first row of denticles $(x)$ can be measured (Table 1). The width of the embryo (d) serves as an internal standard to normalize for variations in total cuticle size. $(B)$ rholact homozygous mutant embryos have less ventral cuticles, which can be seen by the reduced length of all denticle rows. The $r h o^{\text {Iac1 }}$ phenotype is less severe than the $r h o^{7 M 43}$ phenotype, in which the first row of denticles is missing entirely (for a similar phenotype, see $D$ ). Also, fusion of denticles from neighboring segments (especially segments 3 and 4) occurs often in $r h o^{7 M 43}$ but virtually never in rholac1. $(C)$ Denticle bands in $r h o^{\text {lac1 }}$ mutant embryos that carry the $8.3-\mathrm{kb}$ HindIII fragment (see Fig. 2) look very much like those in wild-type embryos. The rows of denticles are also more evenly spaced in these partially rescued embryos than in the rholact mutant. $(D)$ The denticle phenotype of embryos mutant for the rhodel1 allele is more severe than that seen in rholac1 mutants. The cuticular phenotype of this deletion mutant is very similar to that observed for $r h o^{7 M 43}$ embryos and includes frequent fusion of adjacent denticle bands. 


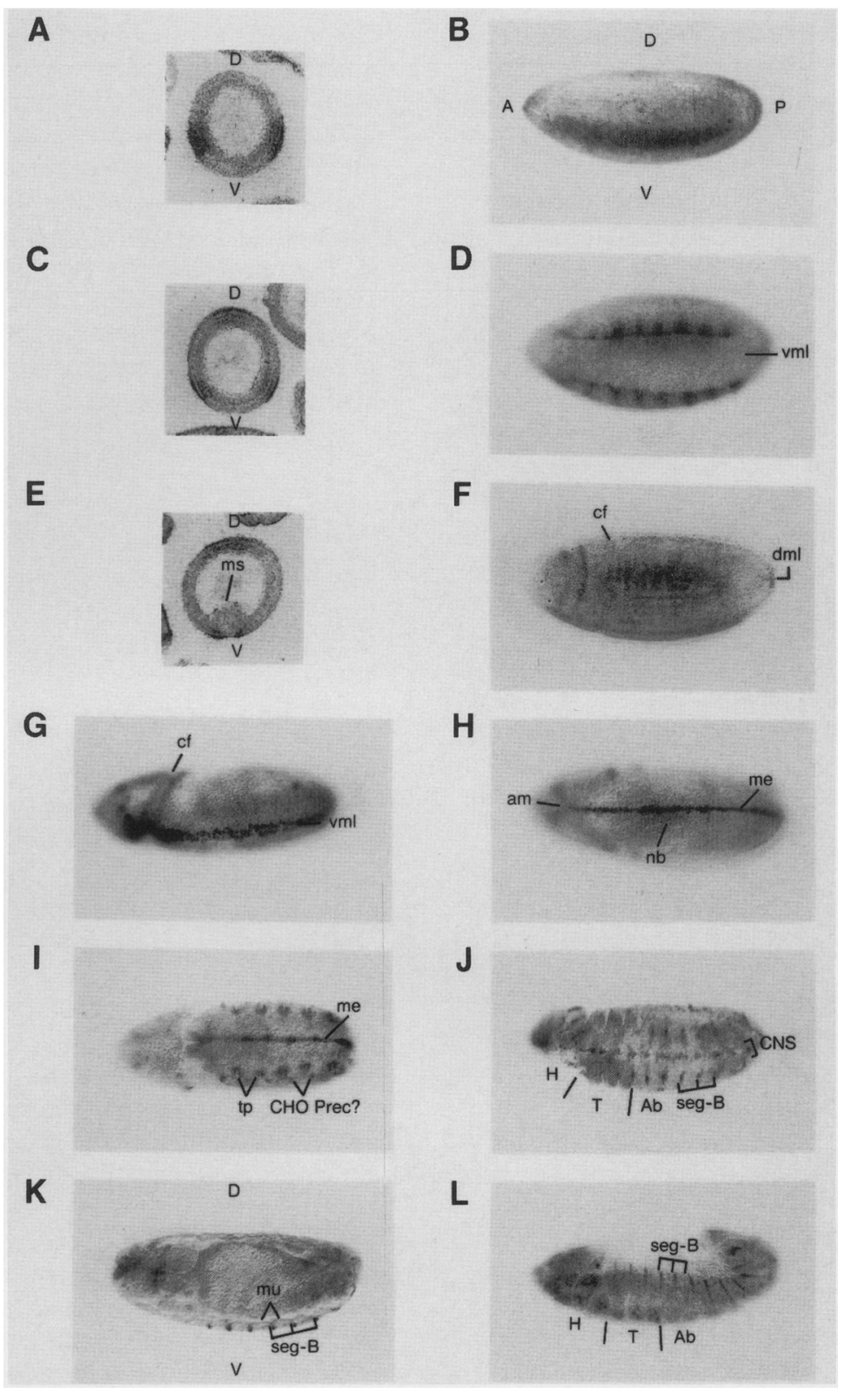

Figure 5. Pattern of expression of rho RNA. (A) A section of an embryo at the early cellular blastoderm stage hybridized with a ${ }^{35}$ S-labeled RNA probe, revealing two ventrolateral signals. $(B)$ Whole-mount embryo at the same stage hybridized with a digoxygenin-labeled DNA probe. $(C)$ Soon after the stage depicted in $A$ and $B$, the signal is localized in three nearly symmetrical locations in transverse sections. Two of the domains correspond to ventrolateral positions, and the third marks the dorsal aspect of the embryo. $(D)$ At about the same stage as in $C$, the longitudinal domains in whole-mount embryos become modulated along the anterior-posterior axis in a pair-rule-like fashion. At this point the ventral margins of the ventrolateral domains become defined by a single sharp row of cells. $(E)$ As gastrulation begins, the ventral furrow forms, so that the ventrolateral label is displaced ventrally. In addition, the domain of expression has narrowed considerably, as shown on this section. (F) A dorsal view at the same stage as in $D$. (G) When the ventral furrow has invaginated almost completely, the ventral label becomes restricted to two single rows of cells on opposite sides of the presumptive mesoderm. $(H)$ As ventral closure takes place, rho-expressing cells from the two halves of the embryo meet to form the mesectodermal cells along the ventral midline. From their location, these cells should also express sim (Crews et al. 1988; Thomas et al. 1988). Note the neuroblasts $(\mathrm{nb})$ in contact with these cells. (I) As germ-band extension proceeds, the mesectoderm continues to label. In each abdominal hemisegment, transient but strong expression is also seen in cells that will form the tracheal pit and in a single large cell that is in a dorsal and posterior position relative to the tracheal pit-most likely the precursor of chordotonal organs. (/) During germ-band retraction, cells in the CNS begin to label. ( $K$ and $L$ ) As germ-band retraction is completed, cells forming the anterior-most row in each abdominal segment label both ventrally and dorsally. In the thoracic segments, this expression is restricted to the dorsal region. Abbreviations in this and subsequent figures are (A) anterior; (Ab) abdominal segments; (am) anterior midgut invagination; (cf) cephalic furrow; (CHO Prec.) chordotonal organ precursor; (D) dorsal; (dml) dorsal midline; (H) head; (me) mesectoderm; (ms) mesoderm; $(\mathrm{mu})$ muscle; (nb) neuroblasts; $(\mathrm{P})$ posterior; (seg-B) segment boundary; $(\mathrm{T})$ thoracic segments; (tp) tracheal pit; (V) ventral; (vml) ventral midline. 
pit and in a single large cell that is dorsal and posterior to the pit (Fig. 5I). The single large cell that expresses rho may be a chordotonal organ precursor, as its location relative to the tracheal pit corresponds well to that of the first chordotonal precursor revealed by the A18 lacZ marker line (Fig. 6A,B). In slightly older embryos, two labeled cells can be seen at this location. Thus, the first labeled cell may divide to give these two cells or, alternatively, another potential precursor may arise de novo. Several other isolated cells in the periphery label less intensely and transiently during this time. The identity of these cells is currently unknown, but some are in the correct locations to be precursors for the ventral chordotonal organ missing in rho mutants, or to be progenitors of the Keilin's organs.

When germ-band retraction begins, rho expression in tracheal pits and along the ventral midline fades rapidly and cells in the CNS begin to label in a segmentally repeated pattern (Fig. 5J). Upon completion of germ-band retraction, segmentally repeated stripes emerge (Fig. $5 \mathrm{~K}, \mathrm{~L}$ ), which are one to two cells wide in the ectoderm at the anterior border of each segment. These ectodermal stripes are seen dorsally (only one cell wide) in both thoracic and abdominal segments (Fig. 5L) but are seen ventrally only in the abdominal segments (Fig. $5 \mathrm{~K}$ ). A small lateral gap separates the dorsal and ventral stripes in abdominal segments. In addition, a single row of cells at the dorsal margin of the epidermis express rho shortly before dorsal closure. Light staining is also seen in two clusters of epidermal cells in the middle of each

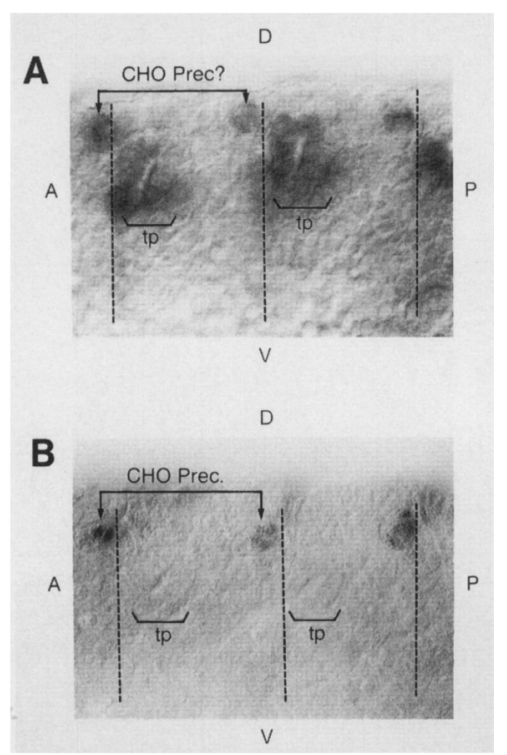

Figure 6. Correlation of the single rho-expressing cell with the chordotonal precursor. (A) A high magnification view of the embryo shown in Fig. 5I. $(B)$ The chordotonal precursors that express lacZ in the A18 line (Ghysen and O'Kane 1989). the position of the first chordotonal precursor relative to the tracheal pit is very similar to the position of the single rho-expressing cell relative to the tracheal pit. These cells are also similar in size, noticeably larger than the surrounding cells. Vertical dashed lines mark the approximate locations of future segment boundaries. abdominal hemisegment. One cluster is found laterally and the other dorsally.

In collections of embryos from heterozygous $r h o^{\text {Iac1 }}$ flies, approximately one-quarter of the blastoderm-stage embryos show only weak and patchy rho expression in the ventrolateral domains. At the germ-band-extended stage, weakly staining embryos are also seen, in which midline expression is clumpy and irregular. This weak and patchy expression pattern is never seen in collections of wild-type embryos. Thus, the P-lacW insertion in $r h^{\text {lac1 }}$ mutant embryos seems to decrease rho expression during early stages of embryogenesis.

\section{lacZ expression pattern in rho ${ }^{l a c 1}$ embryos}

The pattern of $l a c Z$ expression derived from the P-lacW insert in $r h o^{l a c z}$ after blastoderm formation is similar to the expression pattern of the rho transcript as described below. The P-element transposase-lacZ fusion gene is transcribed from the weak transposase promoter. O'Kane and Gehring (1987) have shown that a similar fusion gene gives rise to different expression patterns at different insertion sites. In some cases, the lac $Z$ expression pattern is consistent with that of the gene near the insertion site (Bellen et al. 1989; Bier et al. 1989; Wilson et al. 1989). This also appears to be the case for the PlacW insertion into rho.

lacZ staining in heterozygous $\left(\right.$ rho $\left.^{\text {lac } 1 /}+\right)$ embryos parallels that of the rho transcript along the ventral midline (Fig. 7A), in the CNS (Fig. 7B), and at segment boundaries (Fig. $7 \mathrm{C}, \mathrm{D} \mid$. The blastoderm pattern of rho expression and the transient expression in the tracheal pit and a single cell of each abdominal hemisegment, however, are not mimicked by detectable lacZ expression. Because the orientation of transcription of rho is opposite that of the P-element transposase-lacZ fusion gene and their respective promoters are $>10 \mathrm{~kb}$ apart, it is possible that both the reduced level of early expression of rho RNA in $r$ ho ${ }^{\text {lac1 }}$ mutants and the lack of early lacZ staining are attributable to a differential ability of distinct $r$ ho promoter elements to function across the PlacW insertion.

In addition to strong $\mathrm{lac} Z$ expression in the most anterior row of cells in each abdominal segment during the late stage $(10-12 \mathrm{hr})$ of rho expression, much lighter staining is also transiently visible ventrally in what is likely to be the most posterior row of cells of the preceding segment. Strings of staining cells are also found internally (Fig. $7 \mathrm{D}$ ), in the proventriculus (where the esophagus meets the midgut), in a loop in the hindgut, in rings at the base of the posterior spiracles, and just above the pharynx in two parallel rows that run in an anterior-posterior direction. The same pattern of internal expression has been detected in whole-mount embryos hybridized with rho cDNA, although the label is less intense than in superficial tissues, probably because of limited penetration of the cDNA probe. A common aspect of both ectodermal and internal expression at this later stage is that the arrangements of labeled cells are 
A

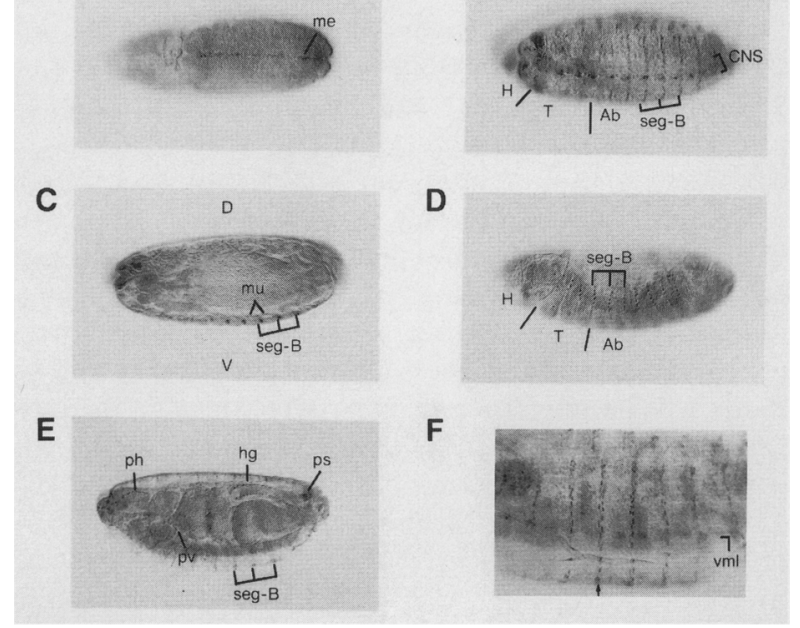

Figure 7. lacZ expression pattern in heterozygous $r h o^{l a c 1} /+$ embryos $(A-E)$ or homozygous rho ${ }^{\text {Iac1 }}$ mutant embryos $(F) .(A)$ A ventral view of an embryo at germ-band extension in which cells in the mesectoderm along the ventral midline are labeled. $(B)$ Following germ-band extension, cells in the CNS begin to label. Eventually, clusters of cells throughout the CNS label, including a cluster of about four cells that lies along the ventral surface of each segment of the CNS, as well as a set of segmentally repeated cells on the dorsal aspect of the mature CNS. $(C-E)$ After germ-band retraction, the lacZ expression pattern becomes complex. $(C)$ Strong staining is seen in the anteriormost row of cells in the ventral region. $(D)$ The staining of the anterior-most row of cells is seen in both abdominal and thoracic segments dorsally. This expression is visible only after germ-band retraction is complete (i.e., slightly later than rho RNA expression; see Fig. 4L $\}$ (E) Notable lacZ expression in internal tissues includes the proventriculus (pv), cells above the pharynx (ph), cells forming a loop in the hindgut (hg), which starts at one posterior spiracle and ends at the other, and rings of cells at the bases of the posterior spiracles (ps). (F) lacZ expression in $r h o^{\text {lac1 } 1 / r h o l a c 1}$ mutant embryos differs from the pattern observed in $r h o^{i a c 1} /+$ embryos, in that there are two rows of strongly labeled ventral cells instead of one. The nuclear localization of the lacZ fusion gene product is likely to be a consequence of the nuclear localization of P-element transposase to which $l a c Z$ is fused.

primarily in linear arrays rather than in sheets or clusters.

The lacZ expression in homozygous $r h o^{\text {lac1 }}$ mutants is very similar to that in heterozygous embryos. The only exception is that instead of a single row of strongly expressing cells located ventrally in the most anterior row of each segment, mutants have two strongly labeled rows that are irregularly arranged in the anterior-most part of each abdominal segment (Fig. 7F).

\section{Discussion}

The rho locus has been cloned by plasmid rescue, using the P-lacW insertion in the $r$ holac1 mutant. An $8.3-\mathrm{kb}$ genomic piece of DNA that includes much of the rho transcription unit shows significant rho function in em- bryos. In the rhodel1 mutant, only genomic sequences from the rho transcription unit are deleted, and the mutant phenotype is even stronger than that of $r h o^{\text {lac1 }}$, from which it was derived. The P-lacW insertion in $r h^{\text {lac1 }}$ is most likely in the promoter of the rho gene and leads to reduced and patchy rho expression in rholac1 mutant embryos. The rholac1 insertion induces $l a c Z$ expression in patterns that closely resemble the rho expression profile after $5 \mathrm{hr}$ of embryogenesis. As discussed below, the complex expression pattern of rho recapitulates the many facets of the rho phenotype.

\section{Correlation between tho expression and mutant phenotypes}

Early rho expression in ventrolateral strips at the cellular blastoderm correlates with the region of the embryonic fate map predicted to be the domain of rho activity (Mayer and Nüsslein-Volhard 1988). As judged from the expression of $r$ ho in mesectodermal cells, it appears that the domain of rho expression may eventually include or overlap with the domain expressing sim. Because mutations in rho and sim appear to affect separate adjacent longitudinal domains of cuticle (Mayer and NüssleinVolhard 1988), the precise domains in which these two genes are initially expressed will be important to determine. There are other features of blastoderm expression that correlate with additional aspects of the cuticular phenotype. Thus, a dorsal strip of expression is seen in the blastoderm, and dorsal closure is defective in rho mutant embryos. There is also early expression in the head region, and mutant embryos exhibit head defects resulting in a pointed head skeleton.

Late rho expression, as revealed by in situ hybridization and by lac $Z$ fusion gene expression, correlates with other aspects of the rho phenotype. For instance, expression is seen along the ventral midline in the mesectoderm and later in cells along the midline of the CNS. In rho mutants, the CNS defects seem localized mostly to a region near the ventral midline (Mayer and NüssleinVolhard 1988; R. Jacobs, pers. comm.). At the germ-band extended stage, rho is expressed in tracheal pits. This may correlate with the observed frequent breaks in major tracheal trunks and general disorganization of finer tracheal branches in rho mutant embryos. Although the lac $Z$ pattern-closely mimics features of rho expression, it does not reproduce the entire pattern of rho expression, a point worth noting with regard to the use of pattern detecting P-element vectors.

In the PNS of mutant rho embryos, two of the five lateral chordotonal organs are missing in abdominal segments. One of the chordotonal organs removed in the mutant is the most anterior one, which is the first to form in the lateral cluster of a wild-type embryo (Bodmer et al. 1989). Most likely, its precursor also fails to form or to differentiate, as no constituents of this chordotonal organ can be detected with markers that label chordotonal organs and their precursors. At about the same time that the first chordotonal organ precursors divide $5 \mathrm{hr}$ after fertilization; Bodmer et al. 
1989; Ghysen and O'Kane 1989), rho is transiently expressed in a single cell and then in two cells located in a dorsal and posterior position relative to the tracheal pit in each abdominal hemisegment. These cells are very near, if not at, the site where the first chordotonal precursors arise (Bodmer et al. 1989; Ghysen and O'Kane 1989). The large size of the initial single cell also suggests that it may be a PNS precursor, as cells surrounding the large $\beta$-gal-expressing cell in the lac $Z$ marker line are consistently smaller than the precursor cell. Thus, the deletion of the lateral chordotonal organs may be the result of a requirement of some function that rho normally provides for the specification of the precursor cell(s). The absence of two chordotonal organs in rho mutants may imply that the earliest chordotonal precursor gives rise to two chordotonal organs. This notion is consistent with the observation that the five lateral chordotonal organs may derive from only two primary precursors (Ghysen and O'Kane 1989; V. Hartenstein, pers. comm.|. Alternatively, the two precursors for the two missing chordotonal organs may arise independently, one after the other.

After $10 \mathrm{hr}$ of embryonic development, rho expression is primarily in linear arrays of cells in the endoderm and ectoderm. The ectodermal expression includes the most anterior row of cells in each abdominal segment and, transiently, the most posterior row of cells of the previous segment. In the rholac1 mutant, two irregular rows of ventral cells at the anterior border of each segment express lacZ. This alteration of the normal expression pattern may be related to the lack of the first row of denticles (normally provided by the most posterior row of cells in the previous segment). The affected cells may either normally express rho or be adjacent to cells that do so. Because cells at the dorsal margin of the epidermis also express rho briefly during this period, the defective dorsal closure in rho mutants may also result from a failure of these cells to act as boundary cells.

A number of factors may underlie the muscle defects in rho mutant embryos. The apparent absence or disarray of some longitudinal and oblique muscles may reflect defects at the segment boundaries, as these muscles have segment boundary attachment sites in wild-type embryos. Evidence for an intimate dependence of the muscle pattern on the location of attachment sites in rho mutant embryos is consistent with this interpretation. Alternatively, muscle defects may be secondary to other ectodermal or mesectodermal abnormalities. The ventral displacement of the ventral and lateral portions of the remaining muscle pattern may be the result of a corresponding shift of epidermal cues that result from loss of more ventral positional information (as evident from cuticular defects|. rho may also play a direct role in muscle development, as some muscles appear to be missing entirely and mesodermal cells are adjacent to rho-expressing cells of the mesectoderm early in development.

No gross phenotypes have been associated with any of the internal tissues expressing rho. We note, however, that virtually all tho expression is in linear arrays of cells, often at known boundaries. The rows of rho-expressing cells at the segment boundaries, at the dorsal margin in the proventriculus, and at the base of the posterior spiracles mark obvious morphological boundaries. rho expression along the ventral midline in the mesectoderm also marks a boundary, namely that between the two halves of the embryo and between mesoderm and neuroectoderm. It is possible that the labeling of cells in the hindgut and above the pharynx also corresponds to some unknown boundaries.

It is interesting that three potential TATA box motifs are found upstream of the $5^{\prime}$ end of transcribed rho sequences. Whether different start sites may be used for different components of the complex rho expression pattern remains to be determined.

In summary, during early blastoderm stages, rho may act to divide the embryo along the dorsoventral axis into longitudinal strips. Anterior-posterior information may also be integrated at this stage, because double segment modulation of the dorsoventral domain is seen shortly before ventral furrow formation. rho may subsequently function to define the first chordotonal precursor cells and still later to specify boundaries, including those defining details of the anterior-posterior axis. Thus, rho provides a striking example where a single zygotic gene is involved in interpreting both dorsoventral and anterior-posterior cues. The hypothesis that rho first functions to set up dorsoventral pattern in the blastoderm and then is subsequently required for unrelated developmental choices, such as sensory organ specification, is similar to the proposal that the segmentation genes fushi tarazu (ftz) and even-skipped (eve) are required early to elaborate anterior-posterior pattern and later to specify cells in the CNS (Doe et al. 1988a,b). Together, these data lend support to the idea that primary patterning genes are, in fact, reused later during nervous system development.

\section{Potential function of the rho protein}

The rapid RNA turnover, as evident from the dynamic rho RNA expression pattern, together with the PEST sequence found in the predicted protein sequence, suggests that the rho protein may be only transiently found in rho-expressing cells. The prediction of an integral membrane protein may imply a cell interaction role for $r h o$. It may act as part of a receiving pathway, because most, if not all, rho phenotypes can be associated with rho expression in cells that are affected by the mutation. It is also possible that rho acts as a signal to adjacent cells. The other gene products with which rho interacts are unknown; however, there are several obvious candidates. The zygotic dorsoventral pattern must be connected in some way to the maternal-effect loci required for establishing dorsoventral cues. Another obvious set of genes with which rho may interact include zygotic genes active in neighboring longitudinal stripes, such as $s i m$ or $d p p$. The unexpected finding that rho and sim may be expressed in the same cells in the mesectoderm makes interaction between these two genes an inter- 
esting possibility. There may be interactions between rho and other genes within the same ventrolateral group as rho (i.e., $S$, spi, and pnt). It is worth noting in this context that double mutants of rho with pnt, but not with $S$ or spi, have a stronger CNS phenotype than either single mutant alone, although the PNS phenotype of double and single mutants is the same (E. Bier, unpubl.). Finally, tho and other members of the ventrolateral group may also interact with those genes that determine the formation of neuroblasts (e.g., the neurogenic loci). The neurogenic loci are required for the development of epidermis in the ventral neurogenic region; loss-of-function mutations in these genes lead to hypertrophy of neurons at the expense of epidermis (Lehmann et al. 1983|. The neurogenic region overlaps the domain of action of the ventrolateral genes. Interestingly, a set of transcripts within one complex neurogenic locus $[E n-$ hancer of split [Knust et al. 1987)] are expressed during blastoderm stages in a pattern very similar to that of $r h o$. The identification of gene products with which the putative rho protein interacts will be an important goal for future studies.

\section{Methods}

Fly stocks

All genetic markers and chromosome balancers used are described in Lindsley and Grell (1968). The $\Delta 2-3$ stock was obtained from W. Engels, and the $r$ ho ${ }^{7 M 43}$ allele was obtained from C. Nüsslein-Volhard.

\section{Reversion of the lethality of the rholac1 insertion}

The $r h o^{\text {lac1 }}$ insert was remobilized in the presence of a transposase source [the $\Delta 2-3$ chromosome (for genetic details, see Robertson et al. 1988)]. Revertants were selected by the loss or reduced expression of the P-element marker gene white. Southern blot analysis revealed that those revertants that are still homozygous-lethal retain P-element sequences. In the rho ${ }^{\text {del1 }}$ mutant, a $5.0-\mathrm{kb}$ segment of DNA has been deleted that includes the $l a c Z$ gene in P-lacW and $0.5-0.8 \mathrm{~kb}$ of flanking genomic sequences at the $5^{\prime}$ end of the transposase $-l a c Z$ fusion gene. The white gene is still functional, although the eye color in this mutant is reduced relative to that in $r h o^{1 a c 1}$ flies. A significant proportion $(60 \%)$ of the revertants, however, are homozygous-viable and fully complement $r h o^{7 M 43}$, unlike $r h o^{\text {lac1 }}$. No P-element remnants were seen among the fully viable revertants. This demonstrates that the P-element insertion is the cause of the lethality and of the rholac1 mutation.

\section{Transformation of flies with rho genomic sequences}

The 8.3-kb genomic HindIII fragment (Fig. 2A) was inserted into pW8 (Klemenz et al. 1987). Because pW8 has no HindIII site available for cloning, the genomic fragment was first subcloned into the HindIII site of the Bluescript polylinker, flanked by $X b a I$ and $K p n I$ sites. This fragment was then inserted into pW8. The resulting plasmid pWRyn was introduced into the germ line of transposase ( $\Delta 2-3)$-expressing flies by standard injection methods (Rubin and Spradling 1982). Nine independent transformants were obtained, and one of these was analyzed in detail. Attempts to construct $\mathrm{P}$ elements that contain larger pieces of genomic DNA with additional sequences at the $5^{\prime}$ end have been unsuccessful thus far.

\section{Testing $p$ WRyn transformants for rho function}

A transformant (RynA-3) with pWRyn on the X chromosome was made homozygous (hemizygous) in rholac1 or $\mathrm{rho}^{7 M 43}$ genetic backgrounds. This insertion partially rescued rho to produce viable larvae that did not, however, survive to adulthood. RynA-3/RynA-3, rho/TM3 flies were outcrossed to flies homozygous or hemizygous for RynA-3/and rho/ + progeny homozygous or hemizygous for RynA-3 were crossed to each other. Embryos were then collected on grape plates with a small amount of yeast. Embryonic lethality was scored after $36 \mathrm{hr}$ at $25^{\circ} \mathrm{C}$ by counting the number of unhatched embryos and the number of chorions left by emerging larvae. (The sum of these closely approximates the total number of eggs deposited).

Cuticles from unhatched 36-hr embryos were prepared by dechorionating embryos in $50 \%$ bleach $15.25 \%$ sodium hypochlorite), washing them in $0.7 \% \mathrm{NaCl}$ and $0.1 \%$ Triton $\mathrm{X}-100$ $\left(\mathrm{NaCl} /\right.$ Triton), fixing in acetic acid and glycerol $(4: 1)$ at $65^{\circ} \mathrm{C}$ for $1 \mathrm{hr}$, and rinsing in $\mathrm{NaCl} / \mathrm{Triton}$. Embryos were then dried down on slides and mounted in Hoyer's medium. The cuticles were examined using a $20 \times$ objective lens with Nomarski optics and a micrometer scale in the eyepiece. The length of the first row of denticles in the third and fourth abdominal segments, as well as the width of the embryos between these segments, was tabulated for all embryos that were orientated with the ventral side either up or down.

\section{Anti- $\beta$-gal staining of embryos}

Embryos were dechorionated with bleach, rinsed with $\mathrm{NaCl}$ / Triton, and fixed with equal volumes of $4 \%$ formaldehyde in $0.1 \mathrm{M}$ sodium phosphate $(\mathrm{pH} 7.2)$ and heptane. The embryos were then devitellinized with equal volumes of $90 \%$ methanol and heptane, rehydrated with $0.1 \mathrm{M}$ sodium phosphate and $0.3 \%$ Triton X-100, and blocked with $2 \%$ bovine serum albumin. The antibody incubations and rinses were all done in the above buffer. The rabbit anti- $\beta$-gal (Cappel) was used at $1: 4000$, and the biotinylated goat anti-rabbit/Avidin D-HRP (Vector Laboratories, PK-4001), at $1: 200$. After reacting HRP with diaminobenzidine, the samples were dehydrated in ethanol, cleared in xylene, mounted on slides with Permount (Fisher), and examined under a microscope with Nomarski optics.

In situ hybridization to RNA in sections or whole-mount embryos

In situ hybridization of ${ }^{35} \mathrm{~S}$-labeled RNA probes to cryostat sections was performed according to Vaessin et al. (1987). In situ hybridization to whole-mount embryos was done following the method of Tautz and Pfeifle (1989), using digoxygenin-labeled probes (Boehringer-Mannheim, 1093 657) synthesized according to the Boehringer-Mannheim protocol. Briefly, embryos were fixed in $1.6 \mathrm{ml}$ of $0.1 \mathrm{M}$ HEPES $(\mathrm{pH} 6.9), 2 \mathrm{~mm}$ $\mathrm{MgSO}_{4}, 1 \mathrm{mM}$ EGTA plus $0.4 \mathrm{ml} \mathrm{20 \%}$ paraformaldehyde, and 8 $\mathrm{ml}$ heptane with vigorous shaking for $15 \mathrm{~min}$. The embryos were then treated with $90 \%$ methanol, followed by PBS plus $4 \%$ paraformaldehyde, rinsed in PBS plus $0.1 \%$ Tween- 20 (PBT), and digested for $5 \mathrm{~min}$ with $50-100 \mu \mathrm{g} / \mathrm{ml}$ nonpredigested proteinase K. Digestion was stopped by the addition of 2 $\mu \mathrm{g} / \mathrm{ml}$ glycine in PBT. Following two washes in PBT, the embryos were refixed in PBS plus 4\% paraformaldehyde for $20 \mathrm{~min}$ and then washed five times in PBT. Embryos were then slowly 
exchanged from PBT into hybridization solution $150 \%$ formamide, $5 \times$ SSC, $100 \mu \mathrm{g} / \mathrm{ml}$ sonicated salmon sperm DNA, 50 $\mu \mathrm{g} / \mathrm{ml} \mathrm{heparin,} 0.1 \%$ Tween-20) and incubated for $1 \mathrm{hr}$ at $45^{\circ} \mathrm{C}$. To approximately $100 \mu \mathrm{l}$ of settled embryos, $50 \mu \mathrm{l}$ of hybridization solution containing one-tenth of a probe (made from the Boehringer-Mannheim kit) was added after denaturation at $80^{\circ} \mathrm{C}$ for $10 \mathrm{~min}$. Hybridization was carried out at $45^{\circ} \mathrm{C}$ overnight. The embryos were then exchanged into PBT over the course of six 20 -min washes (all at $45^{\circ} \mathrm{C}$ ). An alkaline phosphatase-conjugated antibody to digoxygenin, which was previously preabsorbed with fixed embryos, was then applied to embryos for $1 \mathrm{hr}$ (1:2000 dilution of the Boehringer-Mannheim preparation). The unbound antibody was then washed off, and the alkaline phosphatase reaction was carried out with nitro blue tetrazolium (NBT) and stopped by washing in PBT. Embryos were cleared with xylene and mounted with Permount.

\section{Molecular techniques}

Plasmid rescue from minipreps of fly DNA was performed according to Pirrotta (1986). Other cloning techniques followed standard procedures, as in Maniatis et al. (1982). In situ hybridization to polytene chromosomes used the chromosome squash procedure of Gall and Pardue (1971) and a protocol of hybridiza. tion with biotinylated probes (Langer-Safer et al. 1982).

\section{Acknowledgments}

We thank C. Nüsslein-Volhard for providing the $r h o^{7 M 43}$ allele, Rolf Bodmer and Volker Hartenstein for helpful comments about the rho phenotype, Susan Shepherd and Ellsworth Grell for advice with genetics, Robert Carretto and Sandra Barbel for considerable help with tissue in situ hybridization, Denise Muhlrad for help in determining features of the genomic sequence, Larry Ackerman for unfailing assistance with photography, Temple Smith for running his computer program to make predictions based on the deduced rho protein sequence, Ed Giniger for comments on the manuscript, Katherine Prewitt for patient preparation of the manuscript, and Kathryn Burton Bier for her assistance with injection of pWRyn and the isolation of transformant lines. L.Y.J. and Y.N.J. are Howard Hughes Medical Institute investigators.

\section{References}

Anderson, K.V., L. Bokia, and C. Nüsslein-Volhard. 1985a. Establishment of dorsal-ventral polarity in the Drosophila embryo: The induction of polarity by the Toll gene product. Cell 42: 791-798.

Anderson, K.V., G. Jürgens, and C. Nüsslein-Volhard. 1985b. Establishment of dorsal-ventral polarity in the Drosophila embryo: Genetic studies on the role of the Toll gene product. Cell 42: 779-789.

Anderson, L.V. 1987. Dorsal-ventral embryonic pattern genes in Drosophila. Trends Genet. 3: 91-97.

Bellen, H.J., C.J. O'Kane, C. Wilson, U. Grossniklaus, R. Pearson, and W.J. Gerhring. 1989. P-element-mediated enhancer detection: A versatile method to study development in Drosophila. Genes Dev. 3: 1288-1300.

Bier, E., L. Ackerman, S. Barbel, L.Y. Jan, and Y.N. Jan. 1988. Identification and characterization of a neuron-specific nuclear antigen in Drosophila. Science 240: 913-916.

Bier, E., H. Vaessin, S. Shepherd, K. Lee, K. McCall, S. Barbel, L. Ackerman, R. Carretto, T. Uemura, E. Grell, L.Y. Jan, and Y.N. Jan. 1989. Searching for pattern and mutation in the
Drosophila genome with a P-lacZ vector. Genes Dev. 3: $1273-1287$.

Bodmer, R., S. Shepherd, J. Jack, L.Y. Jan, and Y.N. Jan. 1987. Transformation of sensory organs by mutations of the cut locus of D. melanogaster. Cell 51: 293-307.

Bodmer, R., R. Carretto, and Y.N. Jan. 1989. Neurogenesis of the peripheral nervous system in Drosophila melanogaster embryos: DNA replication patterns and cell lineages. Neuron 3: 21-32.

Campos-Ortega, J.A. and V. Hartenstein. 1985. The embryonic development of Drosophila melanogaster. Springer-Verlag, Berlin.

Caudy, M., E. Grell, C. Dambly-Chaudiere, A. Ghysen, L.Y. Jan, and Y.N. Jan. 1988. The maternal sex determination gene daughterless has zygotic activity necessary for the formation of peripheral neurons in Drosophila. Genes Dev. 2: $843-852$.

Cavener, D.R. 1987. Comparison of the consensus sequence flanking translation start sites in Drosophila and vertebrates. Nucleic Acids Res. 15: 1353-1361.

Crews, S., J. Thomas, and C.S. Goodman. 1988. The Drosophila single-minded gene encodes a nuclear protein with sequence similarity to the per gene product. Cell 52: 143-151.

Crossley, A.C. 1978. The morphology and development of the Drosophila muscular system. In The genetics and biology of Drosophila. (ed. M. Ashburner and T.R.F. Wright), vol. 2b, pp. 499-560. Academic press, New York.

Doe, C.Q., D. Smouse, and C.S. Goodman. 1988a. Control of neuronal fate by the Drosophila segmentation gene evenskipped. Nature 333: 376-378.

Doe, C.Q., Y. Hiromi, W.J. Gehring, and C.S. Goodman. 1988b. Expression and function of the segmentation gene fushi tarazu during Drosophila neurogenesis. Science 239: 170175.

Doyle, H., K. Harding, T. Hoey, and M. Levine. 1986. Transcripts encoded by a homeo box gene are restricted to dorsal tissues of Drosophila embryos. Nature 323: 76-79.

Eisenberg, D., L. Schwarz, M. Komaromy, and R. Wall. 1984. Analysis of membrane and surface protein sequences with the hydrophobic moment plot. J. Mol. Biol. 179: 125-142.

Gall, J.G. and M. L. Pardue. 1971. Nucleic acid hybridization in cytological preparations. Methods Enzymol. 21: 470-480.

Ghysen, A. and C. O'Kane. 1989. Neural enhancer-like elements as cell markers in Drosophila. Development 105: 35-52.

Hashimoto, C., K. Hudson, and K. Anderson. 1988. The Toll gene of Drosophila, required for dorsal-ventral embryonic polarity, appears to encode a transmembrane protein. Cell 52: $269-279$.

Hultmark, D., R. Klemenez, and W. Gehring. 1986. Translational and transcriptional control elements in the untranslated leader of the heat shock gene $h s p^{22}$. Cell 44: 429-438.

Jan, L.Y. and Y.N. Jan. 1982. Antibodies to horseradish peroxidase as specific neuronal markers in Drosophila and grasshopper embryos. Proc. Natl. Acad. Sci. 70: 2700-2704.

Jan, Y.N., R. Bodmer, A. Ghysen, C. Dambly-Chaudiere, and L.Y. Jan. 1986. Mutations affecting the peripheral nervous system in Drosophila embryos. Proceedings of the UCLA Symposium for Molecular Entomology. 1. Cell. Biochem. 45-56.

Jürgens, G., E. Weischaus, C. Nüsslein-Volhard, and H. Kluding. 1984. Mutations affecting the pattern of the larval cuticle in Drosophila melanogaster. II. Zygotic loci on the third chromosome. Wilhelm Roux's Arch. Dev. Biol. 193: 283-295.

Klein, P., M. Kanehisa, and C. Delisi. 1985. The detection and 
classification of membrane-spanning proteins. Biochim. Biophys. Acta. 815: 468-476.

Klemenz, R., U. Wever, and W. Gehring. 1987. The white gene as a marker in a new P-element vector for gene transfer in Drosophila. Nucleic Acids Res. 15: 3947-3959.

Knust, E., K. Tietze, and J.A. Campos-Ortega. 1987. Molecular analysis of the neurogenic locus Enhancer of split of Drosophila melanogaster. EMBO /. 6: 4113-4123.

Kohl, N.E., E. Legony, R.A. DePinho, P.D. Nisen, R.K. Smith, C.E. Gee, and F.W. Alt. 1986. Human $N-m y c$ is closely related in organization and nucleotide sequence to $C$-myc. Nature 319: 73-77.

Kruys, V., O. Marinx, G. Shaw, J. Deschamps, and G. Huez. 1989. Translation blockade imposed by cytokine-derived UA-rich sequences. Science 245: 852-854.

Landschulz, W., P.F. Johnson, and S.L. McKnight. 1988. The leucine zipper: A hypothetical structure common to a new class of DNA binding proteins. Science 240: 1759-1764.

Langer-Safer, P.R., M. Levine, and D.C. War. 1982. Immunological methods for mapping genes on Drosophila polytene chromosomes. Proc. Natl. Acad. Sci. 79: 4381-4385.

Lehmann, R., F. Jimenez, U. Dietrich, and J.A. Campos-Ortega. 1983. On the phenotype and development of mutants of early neurogenesis in Drosophila melanogaster. Wilhelm Roux's Arch. Dev. Biol. 192: 62-74.

Lindsley, D.L. and E.H. Grell. 1968. Genetic variations in Drosophila melanogaster. Carnegie Institute of Washington Washington, D.C.

Lohs-Schardin, M., C. Cremer, and C. Nüsslein-Volhard. 1979. A fate map for the larval epidermis of Drosophila melanogaster: Localized cuticle defects following irradiation of the blastoderm with an ultraviolet laser microbeam. Dev. Biol. 73: 239-255.

Maniatis, T., E.F. Fritsch, and J. Sambrook. 1982. Molecular cloning: A laboratory manual. Cold Spring Harbor Laboratory, Cold Spring Harbor, New York.

Mayer, U. and C. Nüsslein-Volhard. 1988. A group of genes required for pattern formation in the ventral ectoderm of the Drosophila embryo. Genes Dev. 2: 1496-1511.

Mount, S. 1982. A catalogue of splice junction sequences. $\mathrm{Nu}$ cleic Acids Res. 10: 459-472.

Nüsslein-Volhard, C., E. Weischaus, and H. Kluding. 1984. Mutations affecting the pattern of the larval cuticle in Drosophila melanogaster. I. Zygotic loci on the second chromosome. Wilhelm Roux's Arch. Dev. Biol. 183: 267-282.

O'Kane, C. and W. Gehring. 1987. Detection in-situ of genomic regulatory elements in Drosophila. Proc. Natl. Acad. Sci. 84: 9123-9127.

Pirrotta, V. 1986. Cloning Drosophila genes. In Drosophila, a practical approach (ed. D.R. Roberts), pp. 83-110. IRL press, Oxford, Washington, D.C.

Ralph, W.W., T. Webster, and T.F. Smith. 1987. A modified Chou-Fasman protein structure algorithm. Cabios 3: 211216.

Rao, M.J.K. and P. Argos. 1986. A conformational preference parameter to predict helices in integral membrane proteins. Biochim, Biophys. Acta 869: 197-214.

Robertson, H.M., C.R. Preston, R.W. Phillis, D. JohnsonSchlitz, W.K. Benz, and W.R. Lingels. 1988. A stable source of P-element transposase in Drosophila melanogaster. Genetics 118: 461-470.

Rogers, S., R. Wells, and M. Rechsteiner. 1986. Amino acid sequences common to rapidly degraded proteins: The PEST hypothesis. Science 234: 364-368.

Rubin, G.M. and A. Spradling. 1982. Genetic transformation of Drosophila with transposable element vectors. Science
218: $348-353$

St. Johnson, D.R. and W.M. Gelbart. 1987. decapentaplegic transcripts are localized along the dorsal-ventral axis of the Drosophila embryo. EMBO f. 6: 2785-2791.

Shaw, G. and R. Kamen. 1986. A conserved AU sequence from the 3 ' untranslated region of GM-CSF mRNA mediates selective mRNA degradation. Cell 46: 659-667.

Tautz, D. and C. Pfeifle. 1989. A nonradioactive in situ hybridization method for the localization of specific RNAs in Drosophila embryos reveals a translational control of segmentation gene hunchback. Chromosoma 98: 81-85.

Thisse, B., C. Stoetzel, C. Gorostiza-Thisse and F. PerrinSchmitt. 1988. Sequence of the twist gene and nuclear localization of its protein in endomesodermal cells of early Drosophila embryos. EMBO J. 7: 2175-2183.

Thomas, J., S. Crews, and C.S. Goodman. 1988. Molecular genetics of the single-minded locus: A gene involved in the development of the Drosophila nervous system. Cell 52: $133-141$.

Uemura, T., S. Shepherd, L. Ackerman, L.Y. Jan, and Y.N. Jan. 1989. numb, a gene required in determination of cell fate during sensory organ formation in Drosophila embryos. Cell 58: $349-360$.

Vaessin, H., K.A. Bremer, E. Knust, and J.A. Campos-Ortega. 1987. The neurogenic gene Delta of Drosophila melanogaster is expressed in neurogenic territories and encodes a putative transmembrane protein with EGF-like repeats. EMBO I. 6: 3431-3440.

Villares, R. and C.V. Cabrera. 1987. The achaete-scute gene complex of $D$. melanogaster: Conserved domains in a subset of genes required for neurogenesis and their homology to myc. Cell 50: 415-424.

Wilson, C., R. Pearson, H.J. Bellen, C.J. O'Kane, U. Grossniklaus, and W.J. Gehring. 1989. P-element-mediated enhancer detection: An efficient method for isolating and characterizing developmentally regulated genes in Drosophila. Genes Dev. 3: 1310-1313. 


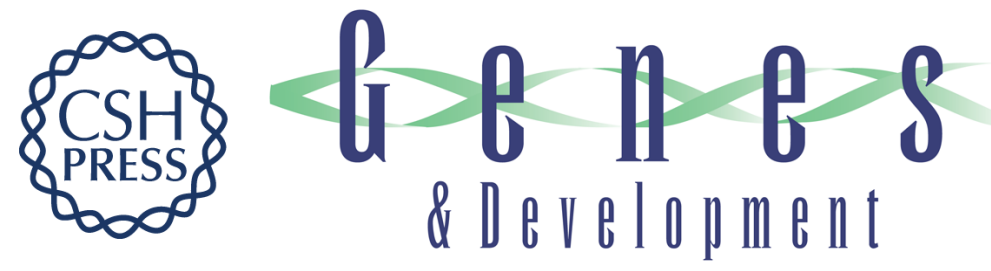

\section{rhomboid, a gene required for dorsoventral axis establishment and peripheral nervous system development in Drosophila melanogaster.}

E Bier, L Y Jan and $Y N$ Jan

Genes Dev. 1990, 4:

Access the most recent version at doi:10.1101/gad.4.2.190

References This article cites 48 articles, 13 of which can be accessed free at:

http://genesdev.cshlp.org/content/4/2/190.full.html\#ref-list-1

License

Email Alerting

Service

Receive free email alerts when new articles cite this article - sign up in the box at the top right corner of the article or click here.

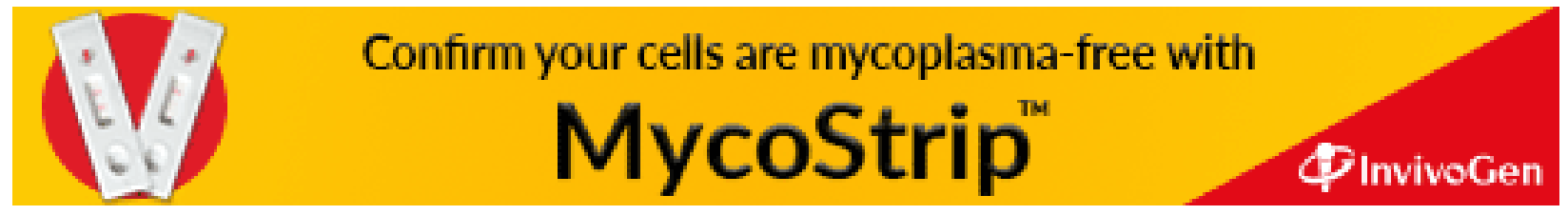

